\title{
A FUZZY PROGRAMMING APPROACH TO INVENTORY CONTROL PROBLEM
}

\author{
Neha Kumari $^{1 *}$, A. P. Burnwal ${ }^{2}$
}

${ }^{1 *}$ Research Scholar, Department of Mathematics, Jharkhand Rai University, Ranchi, Jharkhand, India; ${ }^{2}$ Department of Mathematics, GGSESTC, Bokaro, Jharkhand, India.

Email: ${ }^{1 *}$ oki1978@yahoo.co.in, ${ }^{2}$ apburnwal@yahoo.com

Article History: Received on $28^{\text {th }}$ February 2021, Revised on $6^{\text {th }}$ April 2021, Published on $20^{\text {th }}$ April 2021

\section{Abstract}

Purpose of study: Main aim of this study is to deals with the problem of inventories. Their holding cost, set-up cost, and many more related to that. All the problems are flexible and having fuzzy nature.

Methodology: The model takes the form of a Geometric Programming problem. Hence geometric programming algorithm is used here.

Main Finding: The developed models may be used for a single item with a single constraint of limitation on storage area and multi-item inventory problems.

Application of this study: This study is useful in the area of inventories. There holding cost and set-up cost etc.

The originality of this study: This study may help the stockholders for storing goods and minimizing the cost of holding.

Keywords: Inventory Control Problem, Fuzzy Objectives, Fuzzy Constraints, Membership Function, Compensatory Operator, Weighted Compensatory Operator, Quadratic Achievement Function, Geometric Programming.

\section{INTRODUCTION}

The control of inventories of physical goods is a problem common to all enterprises in any sector of an economy. In any industry, the inventories are essential. The excess inventories are undesirable, which calls for controlling the inventories most profitably. The different types of costs (item cost, ordering cost, carrying cost, understocking cost, overstocking cost, etc.) involved inventory problems that affect the efficiency of an inventory control problem.

In inventory, holding costs, set-up costs, shortage costs, production costs may be flexible with vagueness in their values All these parameters are variable and imprecise. Due to the imprecise nature of the parameters, the problem becomes fuzzy and unsolvable. The concept of fuzzy set theory introduced by (Zadeh, L.A. (1965)) helps in solving the problem. The most important aspect in the fuzzy set theory approach is the compensatory, competitive, or compensatory-cumcompetitive nature of the aggregate operator. Many authors (Burnwal, A.P., Mukerjee, S.N., Singh, D.(1999), Burnwal, A. P.(2008)) have discussed this aspect. Duffin, R.J., Petersen, F.I. \& Zener, C. (1997) gave the theory of Geometric Programming (Rao, S.S.(2013)). Fuzziness concept in Linear Programming with several objectives was due to (Zimmermann, H. J. (1978)).

This paper focuses on Economic Order Quantity (EOQ) inventory model in a fuzzy environment. Compensatory operator, Min operator and Polynomial \& posynominal models of fuzzy geometric programming FGP for the inventory control problem have been devised which is solvable by GP Algorithm.

\section{FORMULATION OF MATHEMATICAL MODEL}

The mathematical model of a constrained multi-objective inventory control problem is stated as follows :

Determine $\quad x=\left(x_{1}, x_{2}, \ldots \ldots \ldots, x_{n}\right)$

which minimizes ' $\mathrm{k}$ ' objectives such as

$$
\begin{aligned}
& f_{1}(x) \\
& f_{2}(x) \\
& f_{3}(x) \\
& f_{k}(x)
\end{aligned}
$$

subject to ' $\mathrm{n}$ ' constraints such as

$$
\begin{aligned}
& g_{1}(x) \leq b_{1} \\
& g_{2}(x) \leq b_{2} \\
& g_{3}(x) \leq b_{3}
\end{aligned}
$$




$$
\begin{aligned}
& g_{n}(x) \leq b_{n} \\
& x \geq 0
\end{aligned}
$$

In symbolic form, Minimize, $F(x)=\left\{f_{1}(x)\right.$,

subject to

$$
\begin{aligned}
& G(x) \leq B \\
& x \geq 0
\end{aligned}
$$

where

$$
\begin{aligned}
G(x)= & \left\{g_{1}(x), \ldots \ldots, g_{n}(x)\right\}, B=\left(b_{1}, b_{2}, \ldots \ldots \ldots, b_{n}\right)^{1} \\
& X=\left(x_{1}, x_{2}, \ldots \ldots \ldots . x_{n}\right)
\end{aligned}
$$

And $\mathrm{f}_{\mathrm{i}}(\mathrm{x})$, for $\mathrm{i}=1,2, \ldots \ldots \ldots \ldots \ldots, \mathrm{k}$ are various costs and $g_{j}(x)$, for $\mathrm{j}=1,2, \ldots \ldots \ldots, \mathrm{n}$ are various constraints. $f_{i}(x)$ and $g_{j}(x)$ are either all polynomials or some polynomials and some polynomials in decision variables. Solving the optimization problem as: Minimizing each $\mathrm{f}_{\mathrm{i}}(\mathrm{x})$ subject to all constraints. Let us write the model (2.1) as Determine ' $\mathrm{x}$ '

subject to

$$
\begin{aligned}
& F(x) \leq P \\
& G(x) \leq B \\
& x \geq 0
\end{aligned}
$$

Where $\mathrm{P}=\left(\mathrm{p}_{1}, \mathrm{p}_{2}, \mathrm{p}_{3}, \ldots \ldots \ldots \ldots \ldots, \mathrm{p}_{\mathrm{k}}\right)$ to ' $\mathrm{k}$ ' objectives function. Assuming that goals are not defined precisely, therefore, the fuzzy model of (2.2) can be given as (2.3). In a real situation, rigid goals vectors P and B do not exist. Therefore, it is more convenient to assign fuzzy (imprecise) goals by allowing some flexibility in the right-hand sides of all the objectives and constraints.

Determine $\mathrm{x}$

subject to

$$
\begin{aligned}
& \mathrm{F}(\mathrm{x}) \underset{\sim}{\leq} \mathrm{P} \\
& \mathrm{G}(\mathrm{x}) \underset{\sim}{\leq} \mathrm{B} \\
& \mathrm{x} \underset{\sim}{\geq 0}
\end{aligned}
$$

Where, the wave symbol ' $\sim$ ' stands for fuzzification of the aspiration levels $b_{j}(j=1$, $b_{n}$ of the given constraints.

Here each ' $\mathrm{p}_{\mathrm{i}}$ ' of the vector $\mathrm{P}$ is increased by $\alpha_{i}$ and each $\mathrm{b}_{\mathrm{j}}$ of B is increased by $\beta$. The model (2.3) has to be defuzzified which is done by using the concept of fuzzy set theory. Linear membership functions denoted by $\mu_{f i}(x)$ and $\mu_{g j}(x)$ respectively for fuzzy goals $f_{i}(x) \underset{\sim}{\geq} p_{i}$ and constraints $g_{j}(x) \underset{\sim}{\geq} b_{j}$ are given by $\mu_{f i}(x)=\frac{\left(P_{i}+\alpha_{i}\right)-f_{i}(x)}{\alpha_{i}}, \forall_{i}$ and $\mu_{g j}(x)=\frac{\left(b_{j}+\beta_{j}\right)-g_{j}(x)}{\beta_{j}}, \forall_{j}$ respectively.

Where, $\mu_{f i}(x), \mu_{g j}(x) \in[0,1]$

The set of achievement functions in different forms such as Linear quadratic \& posynomial using a compensatory operator with normalized weights and without weights as well as min operator is given as $A=\left\{A_{1}, A_{2}, A_{3}, A_{4}, A_{5}, A_{6}, A_{7}\right\}$

Where, $A_{1}=A_{1}(\mu)=\left(\sum_{i=1}^{k} \mu_{f i}(x)\right)+\left(\sum_{j=1}^{m} \mu_{g j}(x)\right)$

$$
\begin{aligned}
& A_{2}=A_{2}(\mu)=\left(\sum_{i=1}^{k} \mu_{f i}(x) * w_{i}\right)+\left(\sum_{j=1}^{m} \mu_{g j}(x) * w_{j}\right) \\
& A_{3}=A_{3}(\mu)=\left(\sum_{i=1}^{k} \mu_{f i}^{2}(x)\right)+\left(\sum_{j=1}^{m} \mu_{g j}^{2}(x)\right) \\
& A_{4}=A_{4}(\mu)=\left(\sum_{i=1}^{k} \mu_{f i}^{2}(x) * w_{i}\right)+\left(\sum_{j=1}^{m} \mu_{g j}^{2}(x) * w_{j}\right) \\
& A_{5}=A_{5}(\mu)=\left(\sum_{i=1}^{k} \mu_{f i}^{w i}(x)\right)+\left(\sum_{j=1}^{m} \mu_{g j}^{w j}(x) * w_{j}\right) \\
& A_{6}=A_{6}(\mu)=\left(\sum_{i=1}^{k} w_{i} * \mu_{f i}^{w i}(x)\right)+\left(\sum_{j=1}^{m} w_{j} * \mu_{g j}^{w j}(x)\right) \\
& A_{7}=A_{7}(\mu)=\min \left\{\mu_{f 1}(x), \ldots, \mu_{f k}(x), \mu_{g 1}(x), \ldots, \mu_{g n}(x)\right\}
\end{aligned}
$$

where, $\sum w_{i}+\sum w_{j}=1$ and $w_{1}, w_{2}, \ldots \ldots \ldots w_{k}, w_{k+1}, \ldots \ldots \ldots, w_{k+n}$ are normalized weights, each $\in[0,1]$ 
The crisp model using $A_{1}$ is given as :

The constrained FGP inventory control problem can be stated as

Maximize $A_{1}(\mu)$

subject to

$$
\begin{aligned}
& \mu_{f i}(x)=\frac{\left(P_{i}+\alpha_{i}\right)-f_{i}(x)}{\alpha_{i}}, \forall_{i} \\
& \mu_{g j}(x)=\frac{\left(b_{j}+\beta_{j}\right)-g_{j}(x)}{\beta_{j}}, \forall_{j} \\
& \mu_{f i}(x) \geq 0, \forall_{i}, \mu_{g j}(x) \geq 0, \forall_{j} \\
& x \geq 0 \ldots \ldots \ldots \ldots . . . . .4)
\end{aligned}
$$

If all fuzzy goals/constraints are not of equal importance then normalized weights are used. The proposed model, in this case, is given as:

Maximize

$$
A_{2}(\mu)
$$

subject to

$$
\begin{aligned}
& \mu_{f i}(x)=\frac{\left(P_{i}+\alpha_{i}\right)-f_{i}(x)}{\alpha_{i}}, \forall_{i} \\
& \mu_{g j}(x)=\frac{\left(b_{j}+\beta_{j}\right)-g_{j}(x)}{\beta_{j}}, \forall_{j} \\
& \mu_{f i}(x) \geq 0, \forall_{i}, \mu_{g j}(x) \geq 0, \forall_{j} \\
& x \geq 0 \ldots \ldots \ldots \ldots(2.5)
\end{aligned}
$$

Some problems involve multiple fuzzy objectives which are dependent on each other. In such a case the overall achievement function may be defined as a quadratic form (Kumar, M., Chakraborty, M., and Singh, D.(1999)) of the membership functions in canonical form. The mathematical model is given as:

$$
\begin{array}{cl}
\text { Maximize } & A_{3}(\mu) \\
\text { subject to } & \mu_{f i}(x)=\frac{\left(P_{i}+\alpha_{i}\right)-f_{i}(x)}{\alpha_{i}}, \forall_{i} \\
& \mu_{g j}(x)=\frac{\left(b_{j}+\beta_{j}\right)-g_{j}(x)}{\beta_{j}}, \forall_{j} \\
& \mu_{f i}(x) \geq 0, \forall_{i}, \mu_{g j}(x) \geq 0, \forall_{j} \\
& x \geq 0 \ldots \ldots \ldots . .(2.6) \\
\text { Maximize } & A_{4}(\mu) \\
\text { subject to } & \mu_{f i}(x)=\frac{\left(P_{i}+\alpha_{i}\right)-f_{i}(x)}{\alpha_{i}}, \forall_{i} \\
& \mu_{g j}(x)=\frac{\left(b_{j}+\beta_{j}\right)-g_{j}(x)}{\beta_{j}}, \forall_{j} \\
& \mu_{f i}(x) \geq 0, \forall_{i}, \mu_{g j}(x) \geq 0, \forall_{j} \\
& x \geq 0 \ldots \ldots \ldots \ldots \ldots(2.7)
\end{array}
$$

The posynomial form of the achievement function may be used. In this case, models are as:

Maximize

$A_{5}(\mu)$

subject to

$$
\begin{aligned}
& \mu_{f i}(x)=\frac{\left(P_{i}+\alpha_{i}\right)-f_{i}(x)}{\alpha_{i}}, \forall_{i} \\
& \mu_{g j}(x)=\frac{\left(b_{j}+\beta_{j}\right)-g_{j}(x)}{\beta_{j}}, \forall_{j} \\
& \mu_{f i}(x) \geq 0, \forall_{i}, \mu_{g j}(x) \geq 0, \forall_{j} \\
& x \geq 0 \quad \ldots \ldots \ldots \ldots . . .(2.8)
\end{aligned}
$$

$$
\begin{array}{ll}
\text { Maximize } & A_{6}(\mu) \\
\text { subject to } & \mu_{f i}(x)=\frac{\left(P_{i}+\alpha_{i}\right)-f_{i}(x)}{\alpha_{i}}, \forall_{i}
\end{array}
$$




$$
\begin{aligned}
& \mu_{g j}(x)=\frac{\left(b_{j}+\beta_{j}\right)-g_{j}(x)}{\beta_{j}}, \forall_{j} \\
& \mu_{f i}(x) \geq 0, \forall_{i}, \mu_{g j}(x) \geq 0, \forall_{j} \\
& x \geq 0 \quad \ldots \ldots \ldots \ldots \ldots . .(2.9)
\end{aligned}
$$

Using Min operation, the model is as:

$$
\begin{array}{ll}
\text { Maximize } & A_{7}(\mu) \\
\text { subject to } & \mu_{f i}(x)=\frac{\left(P_{i}+\alpha_{i}\right)-f_{i}(x)}{\alpha_{i}}, \forall_{i} \\
& \mu_{g j}(x)=\frac{\left(b_{j}+\beta_{j}\right)-g_{j}(x)}{\beta_{j}}, \forall_{j} \\
& \mu_{f i}(x) \geq 0, \forall_{i}, \mu_{g j}(x) \geq 0, \forall_{j} \\
& x \geq 0 \ldots \ldots \ldots \ldots . . .(2.10)
\end{array}
$$

The above models can be solved by the GP algorithm.

\section{SAMPLE PROBLEM: GP Model of Inventory Control}

Minimize the total inventory cost associated with ordering and holding costs while sacrificing certain warehouse space limitations. Let annual demand for each product is ' $\mathrm{N}$ ' units and the rate of demand is ' $\mathrm{k}$ ' per unit time.

If the order size of produce $\mathrm{A}$ is $x_{1}$ units and the stock is depleted at a constant rate ' $\mathrm{k}$ ' then the stock of product A will be zero after $\frac{x_{1}}{k}$ units of time. If $x_{2}$ is the lot size of product $\mathrm{B}$, its stock will be zero after $\frac{x_{2}}{k}$ units of time. Let lot size orders of size $x_{1} \& x_{2}$ respectively to arrive simultaneously.

$\mathrm{N}$ is the annual demand of product $\mathrm{A}, \frac{N}{x_{1}}$ is approximately the number of orders of products per year. With $r_{1}$ as the cost of a single order of product $\mathrm{A}$,

If $\frac{r_{1} N}{x_{1}}$ is the annual ordinary cost of product $\mathrm{A}, \frac{N}{x_{2}}$ is the number of orders of product B per year and ' $r_{2}$ ' is the cost of a single order of product B then $\frac{r_{2} N}{x_{2}}$ is the annual ordering cost of product B.

The total annual ordering cost is $\mathrm{f}_{1}(\mathrm{x})=\frac{r_{1} * N}{x_{1}}+\frac{r_{2} * N}{x_{2}}$

Inventories are depleted at a constant rate, the average inventories are $\frac{x_{1}}{2}$ and $\frac{x_{2}}{2}$

With unit storage costs of $r_{1} \& r_{2}$ for products A \& B respectively,

Average storage cost are $r_{1} * \frac{\left.x_{1}\right)}{2} \& r_{2} * \frac{\left(x_{2}\right)}{2}$

The average annual holding cost is $\mathrm{f}_{2}(\mathrm{x})=r_{1} * \frac{x_{1}}{2}+r_{2} * \frac{x_{2}}{2}$

The storage space requirements of $x_{1} \& x_{2}$ should not exceed $\mathrm{M}$ units.

$x_{1}+x_{2} \leq \mathrm{M}$

The GP model of the inventory control problem is given as :

Determine $X=\left(x_{1}, x_{2}\right)$ which minimizes

$\mathrm{F}(\mathrm{x})=\left\{\mathrm{f}_{1}(\mathrm{x}), \mathrm{f}_{2}(\mathrm{x})\right\}$

subject to $\mathrm{g}(\mathrm{x})=x_{1} / \mathrm{M}+x_{2} / \mathrm{M} \leq 1$

$x_{1}>0, x_{2}>0$.

This problem can be given in any of the above models (2.4 to 2.9).

\section{CONCLUSION}

The developed models may be used for a single item with a single constraint of limitation on storage area and multi-item inventory problems under many limitations, such as their inventory levels, warehouse space, and budget limitations, etc. In multiple objective optimization cases, the objectives and constraints show some degree of dependence over each 
other. The compensatory operator with normalized weights and without normalized weights used in framing the overall achievement function takes into account.

\section{REFERENCES}

1. Burnwal, A. P.(2008). A fuzzy mathimatical programming model for stock control problem. Applied Science Periodical, X(2),126-129.

2. Burnwal, A.P., Mukerjee, S.N., Singh, D.(1999). An additive fuzzy geometric programming for inventory control problem with normalized weights as exponents. Mathematics and statistics in engineering and technology. Narosa publishing house, New Delhi (1999), P 160.

3. Duffin, R.J., Petersen, F.I. \& Zener, C. (1997). Geometric programming: Theory and Application. John Willey and Sons, New York.

4. Kumar, M., Chakraborty, M. and Singh, D.(1999). Quadratic programming Under Fuzzy Environment, Mathematics and Statistics in Engineering and Technology. Narosa Publishing House, New Delhi.

5. Rao, S.S. (2013). Engineering Theory and Practice. New Age International (P) Ltd. Publishers, New Delhi.

6. Zadeh, L.A. (1965). Fuzzy sets. Information and Control, 1, 338. https://doi.org/10.1016/S00199958(65)90241-X

7. Zimmermann, H. J. (1978). Fuzzy programming and linear programming with several objective functions. Fuzzy Sets and Systems, 1, 45. https://doi.org/10.1016/0165-0114(78)90031-3 